\title{
Strategies for Optimal Time Management in Biostatistical Practice
}

\section{Areti Angeliki Veroniki ${ }^{1,2,3 *}$ and Lehana Thabane ${ }^{4,5,6}$}

${ }^{1}$ Department of Primary Education, School of Education, University of Ioannina, Ioannina, Greece

${ }^{2}$ Li Ka Shing Knowledge Institute, St. Michael's Hospital, 209 Victoria Street, East Building, Toronto, Ontario, M5B 1T8, Canada

${ }^{3}$ Institute of Reproductive and Developmental Biology, Department of Surgery \& Cancer, Faculty of Medicine, Imperial College, London W12 ONN, UK

${ }^{4}$ Department of Health Research Methods, Evidence \& Impact; McMaster University, Hamilton, Canada

${ }^{5}$ Departments of Pediatrics and Anesthesia, McMaster University, Canada

${ }^{6}$ Biostatistics Unit, St Joseph's Healthcare, Hamilton, Ontario, Canada

\begin{abstract}
Early-career biostatisticians need to spend a lot of time and energy on enhancing their research and methodology skills to establish themselves as independent investigators. To accomplish these goals, they follow several strategies (e.g., publishing their work in high impact factor journals), which help enhance potential impact of their research and build new collaborations. However, these approaches can be time consuming, and hence time management approaches are necessary. However, time management is not usually taught in typical (bio)statistics courses, and biostatisticians often learn such a skill through a trial-and-error process or mentorship support. The aim of this paper was to discuss key questions that biostatisticians may come up during their career development and to offer potential strategies to tackle them.

We searched PubMed and JSTOR from inception until October 19, 2018, as well as the Google search engine to identify articles discussing or assessing empirically time management in (bio) statistics. We included any study design, but restricted to English articles only. Our search retrieved no relevant articles. This highlights the gap in the existing literature of biostatistics. In this paper, we discuss and provide potential strategies for key issues (e.g., how to prioritize projects in short timeframes) commonly raised by biostatisticians who begin their career and would like to enhance their time management. Overall, time management can result in greater productivity, higher efficiency, less stress, and better opportunities to achieve career goals and advancement. We encourage biostatisticians to make a good plan of their workload, manage their expectations, and always set goals.
\end{abstract}

Keywords: Time management; Statistics; Career development; Health research

\section{Introduction}

Early-career biostatisticians working in health, and in the process to become independent investigators, need to spend a lot of time and energy on enhancing their research and methodology skills, while strengthening their collaborative skills at the same time. They usually start by focusing on strengthening the quality of their research, building on their publication record, gaining experience in obtaining peer reviewed grants, participating in the supervision of graduate students, and expanding their network of national and international collaborations. To accomplish these goals, they follow several strategies, such as 1) disseminating their findings in national and international conferences, 2) organizing critical, in-person meetings with policy makers, biostatistical researchers, health professionals, and researchers from other fields, 3) using social media to promote their research, and 4) publishing their work in high impact factor journals. Although these strategies can help a) enhance potential impact of their research findings, b) build new collaborations with researchers and collaborators from different domains of science facilitating capacity building, and c) allow for exchanging innovative ideas, knowledge and skills, they are time consuming and time management approaches are necessary. It is often the case that in a relatively short time, an informed decision should be taken by a multidisciplinary team of experts using readily available information and knowledge. Accordingly, biostatisticians need to work hard and provide their input in the decision process.

Time management strategies can help improve ability to function more effectively and efficiently, and hence achieve more in a certain amount of time [1]. With tight timelines and large work load, failing to manage time damages productivity and causes stress [2]. Although good time management can result in greater productivity, higher efficiency, less stress, and better opportunities to achieve career goals and advancement [3], it is not usually taught in typical (bio)statistics courses, and biostatisticians often learn such a skill through a trialand-error process or mentorship support [4] (if they are lucky enough to have mentors who are also good at time management). Through this process, a biostatistician finds the tools to fit their strengths, weaknesses, and needs, but it takes time and a lot of effort to build and use these tools effectively.

Traditional academic success is imperative for early-career biostatisticians and time management is an essential skill to achieve. Technological advances (e.g., e-calendars synchronized with emails and mobiles, time management tools that send reminders and inform researchers about deadlines and project performance) have the potential to increase the feasibility of organizing work and everyday tasks. However, technology has, at the same time, brought crisis to people's time management, who often get distracted, and spend time on their phones using, for example, Twitter and Instagram or responding to emails. To make the technological tools we have at our disposal useful for our needs, we should properly and wisely use them to improve our time management skills. For instance, we can respond to our emails

${ }^{*}$ Corresponding author: Areti Angeliki Veroniki, Department of Primary Education, School of Education, University of Ioannina, Ioannina, Greece, Tel: 00302651004324; Fax: 00302651005854; E-mail: averonik@cc.uoi.gr

Received August 01, 2019; Accepted August 30, 2019; Published September 09, 2019

Citation: Veroniki AA, Thabane L (2019) Strategies for Optimal Time Management in Biostatistical Practice. J Biom Biostat 10: 432

Copyright: (c) 2019 Veroniki AA, et al. This is an open-access article distributed under the terms of the Creative Commons Attribution License, which permits unrestricted use, distribution, and reproduction in any medium, provided the original author and source are credited. 
briefly and concisely within a day or two, and for those emails that require a long response we can instead make a phone or skype call to save time.

\section{Benefits of good time management}

Effective time management is one of the most effective skills a biostatistician can have in their life, and can impact every part of their life. This includes avoiding stress, disappointment, poor health, missed opportunities, and even loss of trust from family, colleagues, and friends [5,6]. Effective time management goes hand-in-hand with clear and effective goals, which provide the basis for success and good use of one's time [7]. Biostatisticians usually do not have time to perform all analyses, review and read all relevant manuscripts, attend team meetings and interesting presentations, plan and think the next model to develop, but also be punctual with family and social requirements. Good time management can help biostatisticians with all these issues, i.e. be effective, punctual, productive, and have a good work performance [8].

Impact on work: Effective time management can decrease stress and finalize required tasks on time without being rushed. Setting clear priorities can lead to an efficient work flow and to work without mistakes, which will improve the quality of work. On the contrary, attempting to complete tasks the last minute can sacrifice quality for speed and overextend oneself, which eventually leads to procrastination and poor productivity. Good time management can help biostatisticians to achieve career goals (e.g., publishing research work) and advancement.

Impact on work relationships: Effective time management can also create good team work players with nice workplace relationships. When biostatisticians meet the required deadlines and projects are finalized on time with good quality of work, their colleagues will trust them and will enjoy working with them. However, failing to provide work of certain quality and standards, will include dissatisfaction and frustration in work relationships.

Impact on personal relationships and family: A major advantage of effective time management is its effects on personal relationships and family. Biostatisticians with good time management skills are able to balance work and family time, which as a result can help build good relationships between family members and social relationships. However, poor time management has as a consequence procrastination at work, which can lead biostatisticians to bring work at home in order to make up for the lost time. This can result in insufficient interactions between family members and other personal relationships losing pleasures of family and social life.

Resources on career development and time-management for clinician-investigators are available in the Clinician-Trialist Rounds published in the Clinical Trials [8-10]. However, the field of time management for biostatisticians, currently does not have a highly developed body of literature. The aim of this paper was to discuss key questions that biostatisticians may come up with during their career development and to offer potential strategies to tackle them, and suggestions on how time management can be optimized to help future biostatisticians.

\section{Literature Review}

\section{Literature on time management in biostatistics}

We searched PubMed and JSTOR from inception until October 19, 2018 using the key terms "time management", "biostatistics", and "*statistics" to identify articles on time management in biostatistics (see Appendix). We also searched the Google search engine using the same terms. One reviewer (AAV) screened titles and abstracts (level 1) to identify articles discussing or assessing empirically time management in (bio)statistics. Eligible were studies of any design, but we restricted to English articles only. Interestingly, no relevant articles were retrieved at level 1 , highlighting that the need of such studies in the field of biostatistics.

\section{Time management in practice: Commonly encountered problems and potential strategies to optimize time management}

In this section, we provide commonly encountered questions among early-career biostatisticians and potential strategies to tackle each of them. In Table 1 we summarize our suggestions and provide resources that may be helpful to the reader.

\section{How to keep up to date with the literature?}

A prerequisite to scientific success is to have an in-depth knowledge of the relevant research field. Multiple papers are published every day in the ever-growing network of scientific papers, including health care research and biostatistical methods $[11,12]$. However, to keep up with the rapid changes in medicine and biostatistics can be challenging and it is rarely possible to read and study extensively all papers with related content. This can also be a trade-off spending more time on one's research projects or on reading the latest papers. To contribute to scientific research, one should undoubtedly be familiar with the current state of knowledge and methods used at the frontier of biostatistics.

A potential strategy could be to spend time skimming through the title and abstract of the identified papers, and studying thoroughly only the interesting to the reader papers. 'High-impact' papers should be given priority and be reviewed critically [13-18]. Both free and commercial tools are available to search for relevant papers and set customizable alerts, including Google Scholar (http://scholar.google. com/), CiteSeer (http://citeseer.ist.psu.edu/), PubMed (http://www.ncbi. nlm.nih.gov/pubmed/), and ISI Web of Science (http://isiknowledge. $\mathrm{com} /$ ). Also, creating citation alerts for the papers of high interest, other academics in the field or the biostatistician's publications can be very helpful. One could additionally consider signing up for electronic alerts from specific scientific journals, which offer the option to e-mail the electronic Table of Contents (eTOCs) of each issue that is published, or get an RSS feed from particular journals. RSS feeds allow researchers to track websites of interest by subscribing to the automatic updates. Other approaches include alerts through specific online tools developed to access and identify evidence on a specific topic, such as the medicine evidence alerts Knowledge Translation+ (http://plus.mcmaster.ca/kt/) and EvidenceAlerts (https://plus.mcmaster.ca/evidencealerts/) tools, which provide the users with health care related publications tailored to their interests. Weekly, biweekly, or monthly checks on newly published papers can help staying up to date with the literature. It is also helpful to categorize the identified papers into broadly related papers and into papers of important interest, so as to organize reading.

Another approach could be to attend monthly/weekly journal clubs with an aim to train biostatisticians and/or share knowledge and discuss methods of interest. Journal clubs can particularly help earlycareer researchers expand collaboration and networking, and develop highly qualified personnel who will lead biostatistical projects. Twitterbased journal clubs can be, for example, very helpful in worldwide communication, and generally demonstrate large attendance and long 


\begin{tabular}{|c|c|c|}
\hline Common problems & Potential Strategies & Additional Online Resources \\
\hline $\begin{array}{l}\text { How to keep up to date } \\
\text { with the literature? }\end{array}$ & $\begin{array}{l}\text { - Set customizable alerts to relevant search tools (e.g., Google Scholar, } \\
\text { CiteSeer, PubMed, ISI Web of Science), set citation alerts for papers of } \\
\text { interest, and follow work of other statisticians } \\
\text { - Get eTOCs and RSS feeds from journals of interest } \\
\text { - Have weekly, biweekly, or monthly checks on new publications; study papers } \\
\text { of high interest and skim through title and abstract of remaining papers } \\
\text { - Attend monthly/weekly journal clubs } \\
\text { - Attend online webinars, conferences or poster presentations }\end{array}$ & $\begin{array}{l}\text { https://nursingeducationexpert.com/scientific-literature/ } \\
\text { https://libguides.csu.edu } \\
\text { https://www.healio.com/endocrinology/practice- } \\
\text { management/news/print/endocrine-today } \\
\text { https://www.aje.com/en/arc/keeping-literature-5-ways-track- } \\
\text { and-read-research-online/ } \\
\text { https://bitesizebio.com }\end{array}$ \\
\hline $\begin{array}{l}\text { How to prioritize projects in } \\
\text { short timeframes? }\end{array}$ & $\begin{array}{l}\text { - Set clear and effective goals } \\
\text { - Write down and order projects according to their urgency and importance } \\
\text { - } \text { Estimate time and effort required for each task and set deadlines } \\
\text { - } \text { Focus on the projects involved as the lead author } \\
\text { - Schedule writing time }\end{array}$ & $\begin{array}{l}\text { https://www.liquidplanner.com/blog/how-to-prioritize-work- } \\
\text { when-everythings-1/ } \\
\text { https://www.thriveyard.com/20-tips-on-how-to-prioritize- } \\
\text { work-and-meet-deadlines/ } \\
\text { https://www.brightwork.com/blog/a-practical-guide-to- } \\
\text { prioritizing-project-tasks }\end{array}$ \\
\hline $\begin{array}{l}\text { How to use technology } \\
\text { efficiently? }\end{array}$ & $\begin{array}{l}\text { - Use calendar and to-do list applications to organize work, set reminders for } \\
\text { important tasks, events, and meetings } \\
\text { - Use video-conferencing (e.g., Skype) and file storage applications (e.g., } \\
\text { - Use emails and social media to promote research } \\
\text { - Use Social networking services (e.g., Twitter) stay up to date with the } \\
\text { literature }\end{array}$ & $\begin{array}{l}\text { https://technologyadvice.com/blog/human-resources/ways- } \\
\text { to-use-technology-to-improve-workplace-productivity/ } \\
\text { https://blog.hubspot.com/marketing/productivity-tools-new- } \\
\text { research } \\
\text { https://www.firstpsychology.co.uk/files/Research-report- } \\
\text { FULL-technology.pdf }\end{array}$ \\
\hline $\begin{array}{l}\text { When should we accept } \\
\text { or reject an invitation to } \\
\text { collaborate on a project? }\end{array}$ & $\begin{array}{l}\text { - Important items to consider before deciding on an invitation for collaboration } \\
\text { include: A) Is this a fun project? B) Are the people involved in a project } \\
\text { great people to collaborate? C) What is the outcome of this project? Is a } \\
\text { publication or a similar advantage to be gained? D) What are the deliverables, } \\
\text { expectations, and timelines of the project? E) What resources are available } \\
\text { or will be required to complete the project? } \\
\text { - Hold off for a couple of days before responding; if excitement of collaborating } \\
\text { is still present, then this is a good option. } \\
\text { Consider whether this project will help achieve career goals and vision or if it } \\
\text { will take time from other projects that would better help achieve these goals. }\end{array}$ & $\begin{array}{l}\text { https://www.elsevier.com/connect/a-brief-guide-to-research- } \\
\text { collaboration-for-the-young-scholar } \\
\text { https://www.ncbi.nlm.nih.gov/pmc/articles/PMC3970261/ } \\
\text { https://www.ncbi.nlm.nih.gov/pmc/articles/PMC3652225/ } \\
\text { https://blog.scrunch.com/how-to-politely-decline-a- } \\
\text { collaboration }\end{array}$ \\
\hline $\begin{array}{l}\text { How many papers should } \\
\text { we peer-review per month? }\end{array}$ & $\begin{array}{l}\text { - As an Associate Editor or Statistical Editor peer-review a couple of papers } \\
\text { per month for the underlying journal } \\
\text { - As an external reviewer peer-review as many papers as submitted per year } \\
\text { Do not accept review requests from journals or conferences (e.g. predatory } \\
\text { journals) that are not respectful by the biostatistician }\end{array}$ & $\begin{array}{l}\text { https://malariaworld.org/blog/what-should-we-do-peer- } \\
\text { review-or-not } \\
\text { http://jonathanpeelle.net/blog } \\
\text { https://www.editage.com/insights/peer-review-process-and- } \\
\text { editorial-decision-making-at-journals }\end{array}$ \\
\hline $\begin{array}{l}\text { What and how many } \\
\text { conferences should we } \\
\text { attend per year? }\end{array}$ & $\begin{array}{l}\text { - Attend one or two scientific conferences per yea } \\
\text { Choose according to the biostatistician's research interests, collaborations, } \\
\text { available time, and cost } \\
\text { Attend a conference when there is a specific objective for it (e.g. present } \\
\text { research work, attend a meeting with people related to research goals) }\end{array}$ & $\begin{array}{l}\text { https://hookandeye.ca/ } \\
\text { https://hbr.org/2017/01/how-to-decide-which-conferences- } \\
\text { are-worth-your-time } \\
\text { https://9clouds.com/blog/3-reasons-attend-professional- } \\
\text { conference/ }\end{array}$ \\
\hline
\end{tabular}

Table 1: Commonly encountered problems in the career of a biostatistician along with potential strategies to deal with them.

sustainability [19]. These networks can also help to find related papers and to build a community to discuss papers, collaborations and ideas. Attending online webinars, such as webinars supported by Cochrane (https://training.cochrane.org/cll-webinars) or by Wiley (https:// www.psiweb.org/events/journal-club/journal-club-introduction), conferences or poster presentations, can also help to stay up to date with relevant innovative methods.

\section{How to prioritize projects in short timeframes?}

During a biostatistician's career the research projects he/she gets involved are considerably increasing and the required time to spend on each project is reduced. Therefore, it may be challenging to keep multiple projects on a good track and increase productivity. In such cases, delays can also be caused in the submission and/or publication of these papers. Projects can be well prioritized only when clear goals are set. However, some may believe that setting goals is not that important or others may fear that they can fail reaching a goal. The usual characteristics of effective goals include specificity, clear and realistic expectations, reflection of one's values, effort to achieve them, and good organization.

Success in prioritizing can be reached when goals are written down in a certain order, are visited/discussed on a regular basis along with the desired outcome, and when there is a public commitment to them. Reporting progress regularly in scheduled check-in meetings with the team can be effective to complete a project. Prioritization of projects can start with creating a list of all projects involved, then identify and assess which of those are urgent, important, and "wish to do" projects, and finally order them by the estimated effort needed. Estimating the time and effort for a project's task helps organizing priorities and enables having a realistic plan regarding what can be achieved in a day, week, and/or month. Weekly and monthly to-do lists in addition to a daily list can also help seeing how a task may impact on other projects. Finish 
dates on a project and its tasks are also helpful for setting clearer goals, manage priorities, and have a roadmap on the time a task requires.

A potential strategy to tackle delay of a project submission/ publication may be to invite more people to be involved to enable finishing a project in a reasonable timeframe. This approach can also help to expand collaborations and exchange ideas on how to improve a research project. Another strategy would be to focus on the projects involved as the lead author, which guarantees having control of the research project as the person of interest. A certain deadline can be set when waiting for feedback from co-authors, so as to avoid delays with the submission process. Once comments and suggestions for improvement are received the lead author can accept the co-author suggestions and accommodate their comments that the lead author agrees with. Scheduling specific days for writing manuscripts and grants separately from meetings can also help improve time management with project prioritization. The biostatistician should certainly consider having a flexible priority list, so that when unexpected priority tasks arise, such as revisions on a submitted manuscript or grant, to be able to handle them efficiently.

\section{How to use technology efficiently?}

The right use of technology is a key aspect to improve time management and eventually reach career goals. Computer-use allows for organizing time efficiently, increasing communication within a workspace, faster processing of data, easier retrieval of information, and keeping information up to date. For example, calendar and todo list applications can organize work, set reminders for important tasks, events, and meetings. This helps the researcher to be punctual and increase productivity through focusing on more important workrelated tasks. Other technological tools, including video-conferencing (e.g., Skype) and file storage applications (e.g., Google Drive), can help have a communicative environment and work simultaneously with collaborators from anywhere. Also, emails and social media can optimize time management efficiency, as well as to promote researchers' research. Social networking services (e.g., Twitter) can be used to stay up to date with the literature and find out about other colleagues' work.

Technology can be both a boon and a curse to a researcher's productivity and time management. Obviously, automation of processes and workflows can increase efficiency, but it can also be a work distraction. It should be considered that most of our productivity is achieved by uninterrupted periods of work time, and distractions can affect career goals negatively.

\section{When should we accept or reject an invitation to collaborate on a project?}

Receiving invitations to collaborate on projects shows that a biostatistician starts being established in their career. However, time is not always available to get involved in a new project. Important items to consider before deciding on an invitation for collaboration include: A) Is this a fun project? A good approach is to start getting involved only in projects that are of interest. B) Are the people involved in a project great people to collaborate? An interesting project with horrible collaborators would probably not be fun. C) What is the outcome of this project? Is a publication or a similar advantage to be gained? D) What are the deliverables, expectations, and timelines of the project? E) What resources are available or will be required to complete the project? Funding and citations of this work are important things to consider. Before deciding a biostatistician should also make a list of all the projects that is involved with, set timelines for all these and the upcoming project, and then think thoroughly through this plan if it is possible.

Another potential strategy to consider before deciding on an invitation is to hold off for a couple of days before responding. If the biostatistician is still excited about the idea of collaborating on this project, this suggests that this would be a good option. Another consideration would be to think of the goals that the biostatistician has set for his/her career; would this project help achieve these goals and vision? Does it maybe take time from other projects or ideas that would better help achieve these goals? Of course, work-life balance is another important item to consider before getting involved with numerous projects. All these considerations should be in line with the goals the biostatistician has set for his career. The Oxman-Sackett advice could also be followed as a strategy to manage time better, and to prioritize goals [8].

\section{How many papers should we peer-review per month?}

Biostatisticians receive multiple invitations for peer-review every month. Such articles may be classified in two broad categories: clinical and methodological/statistical. Time permitting, it would be best to peer-review both types of papers, since this is not only an evaluation but also a learning process. However, time is mostly limited and biostatisticians need often to choose between acceptance and rejection of such invitations. Journal editorial boards usually search reviewers with an expertise in the specific area of the paper's research question. For example, they may use the Springer Nature Reviewer Finder (https://reviewerfinder.nature.com), which provides suggestions on peer-reviewers by matching the submitted manuscript with researchers who have previously published similar work. The characteristics of a good reviewer usually include strong scientific background in the required discipline, capability of critically assessing methodology/ analysis, and good time management to return review rapidly [20-22]. Although biostatisticians are expected to be good citizens and may spend a significant time investment, peer-reviews typically count for very little in career advancement and in total there is little concrete benefit.

Since biostatisticians receive multiple invitations within a month to peer-review, it can be challenging to accept them all. Unless a paper is of special interest, a potential strategy to follow would be to peer-review a couple of papers as an Associate Editor or Statistical Editor per month, and as an external reviewer peer-review as many papers as submitted per year. It is better to provide a couple of well-thought reviews instead of many rapid, and low-quality peer-reviews. Another approach would be to not accept review requests from journals or conferences (e.g. predatory journals) [23] that are not of interest to the biostatistician, so as to avoid wasting time.

\section{What and how many conferences should we attend per year?}

As part of their research work and career advancement, biostatisticians need to attend national and international conferences. Although this can help increase networking and disseminate their work, attending multiple conferences a year is time-consuming and expensive. A potential strategy could be to attend one or two scientific conferences per year, which can be chosen according to the research interests, collaborations, available time, and cost. Attending more than two conferences could be time consuming with time taken from other important goals that were previously set for a biostatistician's career.

Another potential strategy could be to attend a conference when there is a specific objective for it. For example, have an oral 
presentation, a poster, or a workshop scheduled to the underlying conference, or maybe intend to attend certain talks/workshop, or an organized a meeting with people related to work and research goals. It is advisable the researcher presents work planned for publication or work that is close to submission. For instance, the conference organized by the American Statistical Association requires a draft paper to be submitted of the presentation that is going to be given. The presentation (or abstract of presentation) can also be used as the first outline for the manuscript. The feedback obtained from the presentation's audience can be helpful with expanding the text in the manuscript and add more details in the discussion section. Therefore, conferences can be a great opportunity to complete ongoing research and even write the first draft of the manuscript [24].

\section{Discussion}

In this paper, we have proposed several strategies to deal with certain time-management issues an early-career biostatistician may encounter. The aim of this paper was not to address all potential issues with time management in biostatistics, but key issues commonly raised by biostatisticians who begin their career and would like to enhance their time management. We encourage biostatisticians to make a good plan of their workload, manage their expectations, and always set goals. Planning is important and helps succeed in one's career; failing to plan can lead to planning to fail. Poor time management can impact negatively in a biostatistician's life such as chronic dissatisfaction with personal and family life, cumulative stress, disappointment, procrastination and failure to achieve career goals.

We suggest strategies to achieve an effective time management during a biostatistician's career. It should be noted though that these are dependent upon one another. For example, prioritizing projects in a short timeframe and accept/reject a project invitation for collaboration require having set a priori clear and effective research goals. Both issues require good collaborations and good time-management skills.

\section{Conclusion}

In summary, time management can result in greater productivity, higher efficiency, less stress, and better opportunities to achieve a biostatistician's ultimate goal that is having a successful career. We encourage biostatisticians to make a good plan of their workload, manage their expectations, and always set goals. We hope our suggested strategies together with other guidance papers on managing a biostatistician's time effectively will help researchers to enhance their academic success.

\section{References}

1. Chase JA, Topp R, Smith CE, Cohen MZ, Fahrenwald N, et al. (2013) Time management strategies for research productivity. West J Nurs Res 35: 155176.

2. Ghiasvand AM, Naderi M, Tafreshi MZ, Ahmadi F, Hosseini M, et al. (2017) Relationship between time management skills and anxiety and academic motivation of nursing students in Tehran. Electronic physician 9: 3678-3684.

3. Arnold E, Pulich M (2004) Improving productivity through more effective time management. The health care manager 23: 65-70.

4. Odueyungbo $A$, Thabane $L$ (2012) Mentoring in biostatistics: some suggestions for reform. J Multidiscip Healthc 5: 265-272.
5. Jackson VP (2009) Time management: a realistic approach. J Am Coll Radiol 6: 434-436.

6. Kressin NR, Saha S, Weaver F, Rubenstein L, Weinberger M (2007) Career and time management strategies for clinical and health services researchers. J Gen Intern Med 22: 1475-1478.

7. Mbuagbaw L, Morfaw F, Kunda JE, Mukonzo JK, Kastner J et al. (2013) Tips for charting the course of a successful health research career. $J$ Multidiscip Healthc 6: 163-168.

8. Oxman AD, Sackett DL (2012) Clinician-trialist rounds: 13. Ways to advance your career by saying 'no' - part 1: why to say 'no' (nicely), and saying 'no' to email. Clin Trials 9: 806-808.

9. Oxman AD, Sackett DL (2013) Clinician-trialist rounds: 14. ways to advance your career by saying 'no' - part 2: when to say 'no', and why. Clin Trials 10 : 181-187.

10. Oxman AD, Sackett DL (2013) Clinician-trialist rounds: 15. Ways to advance your career by saying 'no'--part 3: how to say 'no', nicely. Clin Trials 10: 340 343.

11. Landhuis E (2016) Scientific literature: Information overload. Nature 535: 457 458 .

12. Larsen PO, von Ins M (2010) The rate of growth in scientific publication and the decline in coverage provided by Science Citation Index. Scientometrics 84 $575-603$.

13. Bauer DC (2009) Ten Simple Rules for Searching and Organizing the Scientific Literature. Nature Precedings.

14. Haynes RB, McKibbon KA, Fitzgerald D (1986) How to keep up with the medical literature: I. Why try to keep up and how to get started. Ann Intern Med 105: 149-153.

15. Alper BS, Hand JA, Elliott SG (2004) How much effort is needed to keep up with the literature relevant for primary care? J Med Libr Assoc 92: 429-437.

16. Haynes RB, McKibbon KA, Fitzgerald D, Guyatt GH, Walker CJ, et al. (1986) How to keep up with the medical literature: III. Expanding the number of journals you read regularly. Ann Intern Med 105: 474-478.

17. Haynes RB, McKibbon KA, Fitzgerald D, Guyatt GH, Walker CJ, et al. (1986) How to keep up with the medical literature: II. Deciding which journals to read regularly. Annals of Internal Medicine 105: 309-312.

18. Chase KL, DiGiacomo RF, Van Hoosier GL (2006) Biomedical journals: keeping up and reading critically. Journal of the American Association for Laboratory Animal Science 45: 8-15.

19. Gardhouse Al, Budd L, Yang SYC, Wong CL (2017) \#GeriMedJC: The Twitter Complement to the Traditional-Format Geriatric Medicine Journal Club. J Am Geriatr Soc 65: 1347-1351

20. Simons-Morton B, Abraido-Lanza AF, Bernhardt JM (2012) Demystifying peer review. Health Educ Behav (the official publication of the Society for Public Health Education) 39: 3-7.

21. Mulligan A (2005) Is peer review in crisis? Oral oncol 41: 135-141.

22. Kelly J, Sadeghieh T, Adeli K (2014) Peer Review in Scientific Publications: Benefits, Critiques, \& A Survival Guide. Electronic Journal of the International Federation of Clinical Chemistry and Laboratory Medicine 25: 227-243.

23. Shamseer L, Moher D, Maduekwe O (2017) Potential predatory and legitimate biomedical journals: can you tell the difference? A cross-sectional comparison. BMC Medicine 15: 28.

24. Li G, Jin Y, Mbuagbaw L, Dolovich L, Adachi JD (2018) Enhancing research publications and advancing scientific writing in health research collaborations: sharing lessons learnt from the trenches. J Multidiscip Healthc 11: 245-254. 